\title{
Het voorontwerp voor de wet uitbreiding meldplichten aandeelhouders
}

\author{
Mr.D.P. van Kleef*
}

\begin{abstract}
Op 23 mei 2019 is het voorontwerp voor de wet uitbreiding meldplichten aandeelhouders gepubliceerd. In deze bijdrage wordt het voorontwerp besproken en wordt ingegaan op de openbare consultatiereacties.
\end{abstract}

\section{Inleiding}

Op 23 mei 2019 heeft de minister van Financiën (hierna: de minister) het voorontwerp voor de wet uitbreiding meldplichten aandeelhouders (hierna: voorontwerp) gepubliceerd. ${ }^{1}$ In het voorontwerp wordt voorgesteld dat aandeelhouders voortaan al een melding bij de Autoriteit Financiële Markten (AFM) moeten doen wanneer zij een belang van ten minste $2 \%$ houden in een Nederlandse beursvennootschap met een EER-notering. ${ }^{2}$ Deze verplichting komt boven op de reeds bestaande meldingsplichten voor aandeelhouders. Momenteel ligt de eerste meldingsdrempel op 3\%. In deze bijdrage wordt ingegaan op de hoofdlijnen van het voorontwerp en op de openbare consultatiereacties. Afgesloten wordt met enkele aanbevelingen.

\section{Inhoud van het voorontwerp}

\subsection{Aanleiding}

In het Regeerakkoord 2017-2021 'Vertrouwen in de toekomst' werden verschillende maatregelen aangekondigd om de invloed van bepaalde activistische aandeelhouders die vooral gericht zijn op de korte termijn te verschuiven naar aandeelhouders en andere stakeholders die belang hebben bij waarde-

Mr. D.P. van Kleef is beleidsmedewerker corporate governance en legal counsel bij Eumedion te Den Haag.

1. Het voorontwerp is te raadplegen via de website www. internetconsultatie.nl.

2. De meldingsplichten uit hoofdstuk 5.3 van de $\mathrm{Wft}$ zien op uitgevende instellingen in de zin van art. 5:33 lid 1 onder a Wft. Het gaat daarbij om naamloze vennootschappen naar Nederlands recht waarvan aandelen zijn toegelaten tot de handel op een gereglementeerde markt die gevestigd is in de Europese Economische Ruimte en om enkele buitenlandse entiteiten waarvan aandelen zijn toegelaten tot de handel op een Nederlandse gereglementeerde markt. Zie hierover ook R. Abma \& C.M. Grundmann-van de Krol, Wft uit koers (2). De niet geregelde 'gereglementeerde informatie', Ondernemingsrecht 2019/136, p. 761-764. In deze bijdrage beperk ik mij gemakshalve tot de eerste categorie vennootschappen, de Nederlandse beursvennootschappen met een EER-notering. creatie op de lange termijn. ${ }^{3}$ Zo werd aangegeven dat beursvennootschappen met een jaaromzet van meer dan EUR 750 miljoen de mogelijkheid zouden krijgen om aandeelhouders te vragen, wanneer zij meer dan $1 \%$ van het aandelenkapitaal bezitten, zich als grootaandeelhouder te laten registreren bij de AFM. De minister heeft in verband met de verwachte nalevingskosten van deze variant afgezien en heeft in plaats daarvan in het voorontwerp voorgesteld om een generieke meldingsplicht voor aandeelhouders te introduceren.

\subsection{Aandeelhouders moeten voortaan een melding bij de AFM doen bij een belang van 2\%}

Voorgesteld wordt om deze generieke meldingsplicht op te nemen in het reeds bestaande hoofdstuk 5.3 van de Wet op het financieel toezicht (Wft). In dit hoofdstuk van de Wft zijn - mede ter implementatie van de richtlijn transparantie ${ }^{4}$ regels opgenomen voor de openbaarmaking van door aandeelhouders gehouden zeggenschaps- en kapitaalbelangen in Nederlandse beursvennootschappen. Wanneer een aandeelhouder de beschikking krijgt of verliest over aandelen en/of stemmen waardoor hij een drempelwaarde bereikt, overschrijdt of onderschrijdt, dan moet hij dat melden aan de AFM. ${ }^{5}$ De drempelwaarden zijn in Nederland op 3\%, 5\%, $10 \%, 15 \%, 20 \%, 25 \%, 30 \%, 40 \%, 50 \%, 60 \%, 75 \%$ en $95 \%$ vastgesteld. Het overgrote deel van deze drempelwaarden vloeit voort uit de richtlijn transparantie. Dat geldt niet voor de drempelwaarden van $3 \%, 40 \%, 60 \%$ en $95 \%$. Ten aanzien van die drempelwaarden heeft Nederland gebruikgemaakt van de lidstaatoptie om in afwijking van de richtlijn transparantie lagere en aanvullende drempels vast te stellen. ${ }^{6}$ De drempel van 3\% heeft de wetgever nog niet zo heel lang geleden ingevoerd op advies van de toenmalige Monitoring Commissie Corporate Governance Code (hierna: Commissie Frijns). Een

3. Bijlage bij Kamerstukken II 2017/18, 34700, nr. 34 .

4. Richtlijn 2004/109/EG van het Europees Parlement en de Raad van 15 december 2004 betreffende de transparantievereisten die gelden voor informatie over uitgevende instellingen waarvan effecten tot de handel op een gereglementeerde markt zijn toegelaten en tot wijziging van Richtlijn 2001/34/EG (PbEU 2004, L 390).

5. Art. 5:33 jo. art. 5:38 jo. art. 5:39 Wft. Zie hierover uitgebreid R. Abma e.a., De algemene vergadering van Nederlandse beursvennootschappen (R\&P nr. ONR9), Deventer: Wolters Kluwer 2017/4.4.

6. Art. 3 lid 1 bis jo. art. 9 lid 1 van de richtlijn transparantie. 


\section{Maandblad}

Ondernemingsrecht

van de argumenten die de wetgever daarvoor aanvoerde, was om aan te sluiten bij de drempels uit ons omringende landen zoals het Verenigd Koninkrijk en Duitsland. ${ }^{7}$ Deze aansluiting wordt nu losgelaten. In het voorontwerp wordt met het oog op het belang van langetermijnwaardecreatie door beursvennootschappen voorgesteld om de initiële meldingsdrempel voor aandeelhouders te verlagen van $3 \%$ naar $2 \%$.

\subsection{Rationale van de voorgestelde uitbreiding van de meldingsplichten voor aandeelhouders}

De minister merkt op dat verschillende recente ontwikkelingen, zoals de in 2016 herziene Corporate Governance Code en de herziene richtlijn aandeelhoudersrechten, ${ }^{8}$ het belang van langetermijnwaardecreatie en daarmee samenhangend de dialoog tussen de vennootschap en haar aandeelhouders onderstrepen. Volgens de minister is de langetermijnwaardecreatie bij verschillende vennootschappen onder druk komen te staan ten faveure van (koers)winst op korte termijn. De minister ziet de realisatie van een evenwichtige balans in het aandeelhoudersbestand als een manier om tegenwicht te bieden aan kortetermijngeneigdheid. Volgens de minister kunnen stabiele aandeelhouders die voor langere termijn aan een vennootschap zijn verbonden positief bijdragen aan de vennootschap en tevens voor stabiliteit zorgen. Een duurzame relatie van een vennootschap met haar (langetermijn)aandeelhouders kan - aldus de minister - worden bevorderd door een goede onderlinge en constructieve dialoog tussen aandeelhouders en de vennootschap. De invoering van een nieuwe drempelwaarde van $2 \%$ kan hier volgens de minister aan bijdragen. De minister geeft hiervoor twee argumenten. Ten eerste zou het bestuur van een beursvennootschap hierdoor een breder overzicht krijgen van wie haar grotere aandeelhouders zijn, zodat het bijvoorbeeld gerichter met hen kan communiceren. Ten tweede zou dit (potentiële) aandeelhouders beter in staat stellen bij hun beleggingsbeslissingen voldoende kennis te hebben van (wijzigingen in) stemverhoudingen en belangrijke kapitaalbewegingen. ${ }^{9}$ De minister onderkent dat de nieuwe meldingsplicht tot meer meldingen en daardoor een stijging van de administratieve lasten voor meldingsplichtigen zal leiden. De voordelen die samenhangen met de toename van transparantie in de zeggenschap in Nederlandse beursvennootschappen wegen - aldus de minister - op tegen deze nadelen. Bij een verdere verlaging van de drempelwaarde is daar volgens de minister geen sprake meer van.

\subsection{De meldingsplicht voor aandeelhouders bij een belang van 3\% blijft behouden}

In het voorontwerp wordt er - kort gezegd - voor gekozen om de nieuwe drempelwaarde van $2 \%$ toe te voegen aan de reeds

7. Stb. 2012, 588, Kamerstukken II 2008/09, 32014, nr. 3, Kamerstukken II 2009/10, 32014, nr. 8 en Kamerstukken II 2011/12, 32014, nr. 30.

8. Richtlijn (EU) $2017 / 828$ van het Europees Parlement en de Raad van 17 mei 2017 tot wijziging van Richtlijn 2007/36/EG wat het bevorderen van de langetermijnbetrokkenheid van aandeelhouders betreft (PbEU 2017, L 132).

9. Concept-MvT, p. 2. bestaande drempelwaarden. Dit betekent dat aandeelhouders voortaan al een melding bij de AFM moeten doen wanneer hun long- of bruto-shortpositie de $2 \%$ bereikt, overschrijdt of onderschrijdt (in plaats van, zoals nu het geval is, bij 3\%). Doordat de nieuwe drempelwaarde wordt opgenomen in het reeds bestaande hoofdstuk 5.3 van de Wft zijn ook de reeds bestaande bepalingen over toezicht en handhaving van toepassing. Dit betekent dat de AFM zal toezien op de naleving van deze extra meldingsplicht en indien noodzakelijk handhavend zal optreden. ${ }^{10}$ De minister heeft er uitdrukkelijk niet voor gekozen om de huidige eerste drempelwaarde van $3 \%$ te vervangen door de nieuwe drempelwaarde van $2 \%$. Als reden wordt gegeven dat de reeds bestaande drempelwaarde van 3\% van belang blijft voor beursvennootschappen en andere aandeelhouders in verband met het agenderingsrecht. Op advies van de hierboven al genoemde Commissie Frijns is een paar jaar geleden een koppeling gemaakt tussen de eerste meldingsdrempel voor zeggenschaps- en kapitaalbelangen en de drempel voor het agenderingsrecht. ${ }^{11}$ Sindsdien volgt uit de wet dat een aandeelhouder die alleen of gezamenlijk ten minste $3 \%$ van het geplaatste kapitaal van een naamloze (beurs)vennootschap vertegenwoordigt, het recht heeft om (mits aan bepaalde voorwaarden wordt voldaan) onderwerpen voor de agenda van de algemene vergadering aan te dragen. ${ }^{12}$ De minister wijst erop dat als de verplichting om belangen van $3 \%$ te melden zou komen te vervallen, het zicht op (een deel van) deze categorie deelnemingen zou komen te vervallen. Volgens de minister zou dit onder meer afbreuk kunnen doen aan de dialoog van de vennootschap met belangrijke stakeholders.

\subsection{Vormgeving van de nieuwe meldingsplicht voor aandeelhouders}

In het voorontwerp wordt de drempelwaarde van $2 \%$ toegevoegd aan het artikel waarin substantiële deelneming wordt gedefinieerd, ${ }^{13}$ aan de artikelen waarin wordt aangegeven wat de drempelwaarden zijn, ${ }^{14}$ en aan het artikel waarin een specifiek meldingsregime voor market makers is opgenomen. ${ }^{15} \mathrm{Niet}$ alle artikelen uit hoofdstuk 5.3 van de $\mathrm{Wft}$ waarin nu de eerste drempelwaarde van 3\% wordt genoemd, worden in het voorontwerp ook aangepast. Dit is geen vergissing van de minister, maar een bewuste keuze. Zo wordt het artikel waarin

10. In par. 13 van de Leidraad voor aandeelhouders van de AFM (publicatiedatum: september 2016, update: juli 2017) wordt uitgebreid ingegaan op de bevoegdheden van de AFM en mogelijke sancties.

11. Stb. 2012, 588 en Kamerstukken II 2008/09, 32014, nr. 3.

12. Art. 2:114a BW. Zo moet een aandeelhouder die van dit recht gebruik wil maken ervoor zorgen dat de vennootschap het onderwerp of ontwerpbesluit uiterlijk zestig dagen voor de dag van de algemene vergadering heeft ontvangen. Houders van de certificaten van aandelen die met medewerking van de vennootschap zijn uitgegeven, worden gelijkgesteld met aandeelhouders. Zie hierover uitgebreid Abma e.a. 2017/3.3.

13. Art. $5: 33$ lid 1 onder $f W f t$.

14. Art. 5:38 lid 4, 5:39 lid 3 en 5:41 lid $3 \mathrm{Wft}$.

15. Art. 5:46 lid 2 onder b Wft. Met market makers worden personen bedoeld die in de uitoefening van beroep of bedrijf handelen voor eigen rekening (onderdeel a van de definitie van verrichten van een beleggingsactiviteit in art. 1:1 Wft) 
de handelsportefeuillevrijstelling is opgenomen ${ }^{16}$ niet aangepast, omdat dit volgens de minister zou leiden tot omvangrijke additionele verplichtingen voor de betrokken financiële ondernemingen zonder dat de gewenste vergroting van de transparantie wordt bevorderd. De minister wijst er in dit kader op dat het gaat om deelnemingen die niet worden gebruikt om invloed uit te oefenen. Evenmin wordt het artikel aangepast waarin wordt voorzien in meldingsplichten voor zeggenschaps- en kapitaalbelangen in uitgevende instellingen uit derde landen waarvan Nederland de lidstaat van ontvangst is. ${ }^{17}$ Zoals de minister terecht opmerkt, staat de richtlijn transparantie daaraan in de weg. Deze richtlijn bepaalt namelijk dat lidstaten van ontvangst in hun nationale regelgeving geen strengere meldingsplichten dan de in de richtlijn opgenomen meldingsplichten mogen opleggen aan aandeelhouders. ${ }^{18}$

\section{Bespreking van de consultatiereacties op het voorontwerp}

\subsection{Algemeen}

Het voorontwerp is van 23 mei 2019 tot en met 4 juli 2019 openbaar geconsulteerd. Er zijn dertien openbare consultatiereacties binnengekomen. ${ }^{19}$ Hoewel meerdere respondenten het belang van een goede en constructieve dialoog tussen de vennootschap en haar aandeelhouders onderschrijven, is het overgrote merendeel van de respondenten kritisch over het voorontwerp. Deze kritiek kan op hoofdlijnen worden teruggebracht tot de volgende thema's:

1. Het voorontwerp heeft geen toegevoegde waarde.

2. Door het voorontwerp loopt Nederland verder uit de pas met andere lidstaten.

3. Het voorontwerp leidt tot extra administratieve lasten voor aandeelhouders.

Deze thema's zullen hieronder worden besproken.

\subsection{Het voorontwerp heeft geen toegevoegde waarde}

In de concept-memorie van toelichting wordt erop gewezen dat aandeelhouders momenteel hun belangen van ten minste 3\% moeten melden bij de AFM en dat de herziene richtlijn aandeelhoudersrechten een systeem van aandeelhoudersidentificatie harmoniseert waarmee beursvennootschappen desgewenst grensoverschrijdend beleggers met kleinere belangen

16. Art. 5:46 lid $3 \mathrm{Wft}$.

17. Art. 5:47 Wft.

18. Art. 3 lid 2 van de richtlijn transparantie.

19. De dertien openbare consultatiereacties zijn te raadplegen via de website www.internetconsultatie.nl. Er is een consultatiereactie ingediend door de volgende partijen: AFM, AIMA, Dufas, Eumedion, Euronext, ICGN, Norges Bank Investment Management, Stibbe, VEB, Verbond van Verzekeraars, VEUO, VNO-NCW en een particulier. kunnen identificeren. ${ }^{20}$ Verschillende partijen wijzen in hun consultatiereactie op deze reeds bestaande wettelijke mogelijkheden om een constructieve dialoog tussen beursvennootschappen en aandeelhouders te faciliteren en vinden dat beursvennootschappen nu al voldoende mogelijkheden hebben om een dialoog aan te gaan met hun aandeelhouders. ICGN en het Verbond van Verzekeraars zien daarom de toegevoegde waarde van het voorontwerp niet en Euronext vraagt zich af voor welk probleem het verlagen van de drempel van $3 \%$ naar $2 \%$ een oplossing biedt. AIMA wijst er nog op dat het (in het licht van de bestaande identificatieregeling) moeilijk te begrijpen is op welke wijze een verlaging van de initiële meldingsdrempel zal bijdragen aan een meer duurzame relatie tussen de vennootschap en haar aandeelhouders. Stibbe vreest zelfs dat het voorontwerp het omgekeerde zal bewerkstelligen van wat wordt beoogd. Volgens Stibbe maakt het voorontwerp het voor activistische aandeelhouders mogelijk om met een relatief kleine investering Nederlandse beursvennootschappen publiekelijk onder druk te zetten hun beleid te wijzigen. Verder merken Dufas, Eumedion en de VEB nog op dat het voorontwerp inbreuk makkt op de privacy van beleggers met een thans niet-meldingsplichtig belang. Er wordt op gewezen dat deze groep beleggers (niet zelden privépersonen) voor het eerst wordt geconfronteerd met een meldingsplicht en het gevolg hiervan is dat deze personen voortaan met naam en toenaam zullen worden opgenomen in het publieke meldingsregister van de AFM. Volgens Dufas is deze inbreuk op de privacy disproportioneel ten opzichte van de gewenste transparantie. Ook Eumedion is de mening toegedaan dat het niet proportioneel is om inbreuk te maken op de privacy van voornoemde beleggers en hen onnodig op kosten te jagen. In enkele reacties, waaronder die van de AFM, wordt er expliciet voor gepleit om af te zien van het voorontwerp.

Twee partijen zien wel voordelen in de verlaging van de eerste meldingsdrempel naar 2\%. Zo benadrukt VNO-NCW dat een vennootschap hierdoor eerder kennis kan nemen van een nieuwe, grotere aandeelhouder en desgewenst contact kan opnemen om diens intenties te bespreken. De VEUO wijst erop dat de drempel voor het agenderingsrecht en de eerste meldingsdrempel beide op $3 \%$ zijn vastgesteld en merkt op dat een aandeelhouder met mogelijk activistische oogmerken de vennootschap kan verrassen zonder dat de vennootschap deze actie kan zien aankomen. Daarnaast merken deze partijen op dat door de lagere meldingsdrempel de praktijk wordt ingedamd waarbij een aandeelhouder totdat hij voor het eerst een melding moet doen van zijn belang relatief goedkoop aandelen kan kopen en ervan kan profiteren als de koers stijgt na het

20. Beursvennootschappen kunnen aandeelhouders die ten minste $0,5 \%$ van de aandelen houden, identificeren op grond van de in de Wet giraal effectenverkeer (Wge) opgenomen identificatieregeling. In het wetsvoorstel ter implementatie van de herziene richtlijn aandeelhoudersrechten worden de mogelijkheden daartoe uitgebreid. Zie hoofdstuk 3a van de Wge, art. 3 bis van de herziene richtlijn aandeelhoudersrechten en het wetsvoorstel ter implementatie van die richtlijn (Kamerstukken I 2018/19, 35058, A) 


\section{Maandblad \\ Ondernemingsrecht}

doen van een melding. ${ }^{21}$ VNO-NCW meent dat het voorontwerp ook voordelen voor beleggers heeft. Er wordt op gewezen dat beleggers door het voorontwerp extra informatie wordt geboden over bepaalde concentraties van belangen en dat zij hierdoor beter geïnformeerd en onderbouwd beleggingsbeslissingen kunnen nemen. Opgemerkt wordt dat dit kan bijdragen aan een verbetering van de werking van de financiële markten.

Volgens de minister kan de invoering van de 2\%-drempelwaarde bijdragen aan een goede onderlinge en constructieve dialoog tussen aandeelhouders en de vennootschap. ${ }^{22}$ Mijns inziens is het voorontwerp daarvoor niet nodig. Nederlandse beursvennootschappen hebben namelijk al voldoende mogelijkheden om hun 2\%-aandeelhouders te kennen en met hen een dialoog aan te gaan. Alle aandeelhouders die een belang van $3 \%$ of meer houden, kunnen zij kennen via het publieke meldingsregister van de AFM en de identiteit van aandeelhouders met een belang van ten minste $0,5 \%$ kunnen zij achterhalen via de wettelijke identificatieregeling. ${ }^{23}$

\subsection{Door het voorontwerp loopt Nederland verder uit de pas met andere lidstaten}

Zoals in paragraaf $2.2 \mathrm{al}$ is aangegeven, voorziet de richtlijn transparantie (net als het voorontwerp) in een meldingsplicht voor aandeelhouders van belangrijke deelnemingen in beursvennootschappen. De richtlijn transparantie legt de eerste meldingsdrempel op 5\%. Nederland heeft van de mogelijkheid gebruikgemaakt om (onder meer) lagere drempels vast te stellen en heeft de eerste meldingsdrempel op 3\% gesteld. ${ }^{24}$ Het overgrote deel van de partijen wijst erop dat met de drempelwaarde van $2 \%$ nog verder uit de pas wordt gelopen met de meerderheid van de lidstaten (die in lijn met de richtlijn transparantie de eerste drempelwaarde op 5\% heeft gezet). In meerdere reacties wordt er nog op gewezen dat van alle lidstaten alleen Tsjechië en Portugal een eerste drempelwaarde hebben die onder de $3 \%$ ligt. $^{25}$ AIMA merkt nog op dat de lagere

21. Een aandeelhouder die actief een drempelwaarde bereikt, overschrijdt dan wel onderschrijdt, moet dat onverwijld melden aan de AFM (art. 5:38 Wft). In par. 8 van de Leidraad voor aandeelhouders van de AFM (publicatiedatum: september 2016, update: juli 2017) wordt aangegeven wat onverwijld betekent. Dat betekent volgens de AFM: 'dat de tijd tussen het moment van weten of behoren te weten van het bereiken, over- of onderschrijden van een drempelwaarde of het krijgen of verliezen van één of meer aandelen met een bijzonder statutair zeggenschapsrecht, en het moment dat de AFM de melding ontvangt zo kort mogelijk dient te zijn, gegeven de omstandigheden'. Voor een aandeelhouder die passief een drempelwaarde bereikt, overschrijdt dan wel onderschrijdt, geldt er een langere termijn (zie art. 5:39 Wft).

22. Zie meer uitgebreid par. 2.3.

23. Hoofdstuk 3 a van de Wge. De bruikbaarheid van deze regeling zal worden verbeterd door het wetsvoorstel ter implementatie van de herziene richtlijn aandeelhoudersrechten (Kamerstukken I 2018/19, 35058, A).

24. Stb. 2012, 588. Art. 3 lid 1 bis jo. art. 9 lid 1 van de richtlijn transparantie. Daarnaast heeft Nederland (in afwijking van de richtlijn transparantie) de volgende aanvullende drempels opgenomen: $40 \%, 60 \%$ en $95 \%$.

25. Zie ook Practical Guide ESMA: National rules on notifications of major holdings under the Transparency Directive, ESMA31-67-535, 31 juli 2019. In Portugal ligt de eerste drempelwaarde op $2 \%$ en in Tsjechië ligt deze drempel voor de grotere vennootschappen op $1 \%$. drempelwaarden in zowel Tsjechië als Portugal gekoppeld zijn aan het recht voor aandeelhouders om onderwerpen voor de agenda van de algemene vergadering aan te dragen. Volgens voornoemde partij lijkt de keuze voor $2 \%$ in het voorontwerp arbitrair en is deze niet gekoppeld aan de uitoefening van bepaalde rechten door aandeelhouders. Stibbe meent dat een verdere verlaging van de eerste meldingsdrempel naar $2 \%$ vanuit ondernemingsrechtelijk perspectief geen meerwaarde heeft. De AFM heeft een soortgelijke opvatting.

Daarnaast hebben verschillende partijen opmerkingen gemaakt over de gevolgen van het voorontwerp voor het Nederlandse beleggingsklimaat. Zo vraagt Euronext zich af of het voorontwerp mogelijk een drempel kan opwerpen voor buitenlandse investeerders om hun belangen in Nederlandse bedrijven te vergroten. Voor verschillende partijen is het antwoord op die vraag klip-en-klaar. AIMA wijst erop dat veel internationale beleggers door het voorontwerp zullen worden ontmoedigd om te investeren in Nederlandse beursvennootschappen en meent dat het voorontwerp invloed heeft op het vrij verkeer van kapitaal. ${ }^{26}$ Eumedion meent dat het beleggen in Nederlandse beursvennootschappen door het voorontwerp minder aantrekkelijk kan worden en volgens het Verbond van Verzekeraars schrikt het buitenlandse investeerders mogelijk af.

Verder hebben enkele partijen gevraagd hoe het voorontwerp valt te rijmen met de ambitie van de minister om verdere stappen te nemen voor de verdieping en verbreding van de Europese kapitaalmarktunie. ${ }^{27}$ Volgens de AFM is het voorontwerp een opmaat naar meer fragmentatie binnen Europa en staat het haaks op het streven naar meer geharmoniseerde internationale regelgeving en de kapitaalmarktunie. AIMA spreekt steun uit voor dit standpunt van de AFM. Eumedion en ICGN geven aan voorstander te zijn van meer harmonisatie van de meldingsregels. Volgens Stibbe draagt het voorontwerp bij aan een verdere versplintering van de meldingsplichten en is het zeer de vraag of het voorontwerp een positieve bijdrage zal leveren aan de creatie van een Europese kapitaalmarktunie. De VEB wijst erop dat het voorontwerp indruist tegen level playing field en kan dit niet rijmen met de uitgesproken ambitie van het kabinet om tot de Europese kapitaalmarktunie te komen.

Het is mijns inziens opvallend dat de minister zich inzet voor een verdere verdieping en verbreding van de Europese kapitaalmarktunie en in het voorontwerp voorstelt om in afwijking van de richtlijn transparantie (die de eerste meldingsdrempel op 5\% legt) nationaal nog een extra meldingsdrempel

26. Art. 63 VWEU.

27. Zie Kamerstukken II 2018/19, 22112, nr. 2798. In deze brief valt te lezen dat de Nederlandse, Duitse en Franse ministers van Financiën het initiatief hebben genomen om experts uit de financiële sector te vragen om aanbevelingen te doen voor de toekomst van de kapitaalmarktunie. Deze experts hebben op 9 oktober 2019 hun eindrapport aangeboden aan voornoemde ministers van Financiën (Kamerstukken II 2019/20, 22112, nr. 2829). 
van $2 \%$ in te voeren. Zoals ik hierboven al heb aangegeven, wijkt Nederland op dit moment al af van de eerste meldingsdrempel uit de richtlijn transparantie. In het verleden heeft Nederland namelijk al gebruikgemaakt van de lidstaatoptie om in afwijking van de richtlijn transparantie een lagere eerste meldingsdrempel van $3 \%$ in te voeren. Een van de argumenten die de wetgever daarvoor destijds aanvoerde, was om aan te sluiten bij de drempels uit ons omringende landen. Door de invoering van de eerste meldingsdrempel van $2 \%$ wordt deze aansluiting losgelaten en wordt nog verder uit de pas gelopen bij de overgrote meerderheid van de lidstaten. De invoering van de extra meldingsdrempel van $2 \%$ zal mijns inziens leiden tot extra kosten voor beleggers, hetgeen niet bijdraagt aan de aantrekkelijkheid van de Nederlandse kapitaalmarkt.

\subsection{Het voorontwerp leidt tot extra administratieve lasten voor aandeelhouders}

De minister vindt dat de voordelen die samenhangen met de invoering van de nieuwe drempelwaarde van $2 \%$ opwegen tegen de nadelen daarvan en schat dat aandeelhouders jaarlijks 4500 extra meldingen zullen moeten doen. Het overgrote deel van de partijen wijst erop dat het voorontwerp leidt tot hogere lasten voor aandeelhouders. Eumedion, VEB en VNO-NCW merken nog op dat de inschatting van het aantal meldingen bij de invoering van de drempelwaarde van $3 \%$ fors was onderschat. Eumedion betwijfelt daarom of de geraamde toename van het aantal meldingen wel realistisch is en vraagt zich af of de structurele administratieve lasten in de praktijk niet wederom veel hoger zullen uitpakken voor aandeelhouders. Daarnaast wijst deze partij erop dat de initiële meldingen ten onrechte niet zijn meegenomen in de berekening van de administratieve lasten. Verschillende partijen menen dat het voorontwerp zal leiden tot hogere (overbodige) administratieve lasten en meer complexiteit voor aandeelhouders en hogere toezichtskosten. Volgens ICGN zal het voorontwerp leiden tot significante additionele administratieve lasten voor aandeelhouders voor slechts marginale informatieve voordelen.

De minister onderkent terecht dat de invoering van de 2\%drempelwaarde naar verwachting tot meer meldingen en daardoor een stijging van de administratieve lasten voor meldingsplichtigen zal leiden. Zoals ik hierboven al heb aangegeven, hebben Nederlandse beursvennootschappen al voldoende mogelijkheden om hun 2\%-aandeelhouders te kennen en met hen een dialoog aan te gaan. Gelet hierop is het mijns inziens niet proportioneel om aandeelhouders onnodig op kosten te jagen door de introductie van de drempelwaarde van $2 \%$. Daar komt nog bij dat het - gelet op de ervaringen uit het verleden - nog maar de vraag is in hoeverre de in de conceptmemorie van toelichting opgenomen schatting van de toename van het aantal meldingen realistisch is.

\section{Afsluitende opmerkingen en aanbevelingen}

Door veel partijen is kritisch gereageerd op het voorontwerp. Het is nu aan de minister om te besluiten of het voorontwerp (al dan niet in aangepaste vorm) moet worden ingediend bij de Tweede Kamer. De minister zou zich moeten afvragen welk probleem er wordt opgelost met het voorontwerp. Wat de toegevoegde waarde van het voorontwerp is, zie ik niet goed. Aandeelhouders die een belang van 3\% houden in een Nederlandse beursvennootschap zijn al met naam en toenaam opgenomen in het publieke meldingsregister van de AFM. De identiteit van aandeelhouders met een belang van ten minste $0,5 \%$ kan door beursvennootschappen worden achterhaald via de wettelijke identificatieregeling. ${ }^{28}$ Beursvennootschappen hebben mijns inziens al voldoende mogelijkheden om een goede en constructieve dialoog te voeren met hun $2 \%$-aandeelhouders, een verlaging van de eerste meldingsdrempel naar $2 \%$ is daarvoor niet nodig. Volgens de Aanwijzingen voor de regelgeving $(\mathrm{Ar})^{29}$ wordt tot het tot stand brengen van een regeling alleen besloten indien de noodzaak daarvan is komen vast te staan. ${ }^{30}$ Uit de toelichting op de Ar volgt dat regelgeving noodzakelijk is indien aannemelijk is dat het concrete voorstel een effectieve, efficiënte en evenredige reactie vormt op het maatschappelijke probleem dat aanleiding geeft voor die regelgeving. Daarvoor is vereist dat wordt voldaan aan drie cumulatieve voorwaarden. Deze voorwaarden zijn 'dat voldoende zekerheid bestaat dat de voorgestelde regeling werkelijk zal leiden tot het oplossen of verminderen van dat probleem', 'dat er geen minder bezwarende alternatieven zijn', en 'dat de kosten en lasten daarvan gerechtvaardigd worden door de ernst van het probleem'. ${ }^{31}$ Mijns inziens wordt niet aan deze voorwaarden voldaan en bestaat er onvoldoende grond om tot regelgeving (in de voorgenomen vorm) over te gaan. ${ }^{32} \mathrm{De}$ minister is nu aan zet. Wordt vervolgd.

28. Hoofdstuk 3a van de Wge. De bruikbaarheid van deze regeling zal worden verbeterd door het wetsvoorstel ter implementatie van de herziene richtlijn aandeelhoudersrechten (Kamerstukken I 2018/19, 35058, A).

29. Een circulaire van de Minister-President van 18 november 1992, die nadien herhaaldelijk is gewijzigd. Op de website van het Kenniscentrum Wetgeving en Juridische zaken (www.kcwj.nl) valt te lezen: 'De Aanwijzingen voor de regelgeving vormen het kader dat wetgevingsjuristen van de centrale overheid in acht horen te nemen bij het opstellen van regelgeving.'

30. Ar 2.2.

31. Toelichting op Ar 2.2.

32. Uit de toelichting op Ar 2.2 volgt namelijk het volgende: 'Indien niet aan elke van deze voorwaarden is voldaan, bestaat onvoldoende grond om tot regelgeving (in de voorgenomen vorm) over te gaan. Eventueel kan in zo'n geval een alternatief, minder bezwarend sturingsinstrument worden ingezet, of dient simpelweg van overheidsingrijpen te worden afgezien.' 